\title{
The significance of cultural norms and clinical logics for the perception of possible relapse in rural Northern Norway - sensing symptoms of cancer
}

\author{
Magdalena Skowronski, ${ }^{1}$ Mette Bech Risør, ${ }^{1}$ Nina Foss ${ }^{2}$ \\ ${ }^{1}$ Department of Community Medicine, Faculty of Health Sciences, UiT The Arctic University of Norway; ${ }^{2}$ Department of Health and \\ Care Sciences, Faculty of Health Sciences, UiT The Arctic University of Norway, Tromsø, Norway
}

\begin{abstract}
Little is known about the process from experiencing indeterminate bodily sensations to perceiving them as possible symptoms of cancer relapse. We explore how such processes are related to local values and to clinical practice in rural Northern Norway. One-year ethnographic fieldwork was conducted in a coastal village involving ten key participants residing in the village who had undergone cancer treatment from six months to five years earlier. The village has instability in primary health care staffing, which influences how and when indeterminate bodily sensations are presented to shifting GPs. The participants feel that they have to present clear symptoms, so they hesitate to see the doctor for such bodily sensations. Moreover, the personal evaluation of bodily sensations is embedded in local values in the village. Core values are to contribute to the common good, not be a burden, be positive and avoid focusing on difficult things. Participants' inner dialogues with co-villagers and health personnel lead to not sharing concerns about bodily sensations, even though they might be symptoms of relapse. We suggest a rethinking and relocation of Hay's analysis of social legitimation in sense-tosymptom processes in order to grasp the experiences of cancer in rural Northern Norway.
\end{abstract}

\section{Introduction}

Laila (study participant - personal communication. All names were changed): If I've got high blood pressure or my foot hurts, I think of cancer. [...] So it's kind of... am I

Correspondence: Magdalena Skowronski, Department of Community Medicine, Faculty of Health Sciences, UiT The Arctic University of Norway, Forskningsparken, Sykehusveien 23, 9019 Tromsø, Norway.

Tel.: +47.48340823.

E-mail: msk046@uit.no

Key words: relapse, sense-to-symptom, Northern Norway, primary health care, local values, rural health care.

Contributions: MS: acquisition of data. All three authors: conception, design, analysis and interpretation of data; revising it critically for important intellectual content; critical revision;

final approval of the version to be published.

Conflict of interest: the authors declare no potential conflict of interest.

Funding: the project was funded by the Research Council of Norway.

Received for publication: 3 October 2017.

Revision received: 30 October 2017.

Accepted for publication: 2 November 2017

This work is licensed under a Creative Commons Attribution NonCommercial 4.0 License (CC BY-NC 4.0).

CCopyright M. Skowronski et al., 2017

Licensee PAGEPress, Italy

Qualitative Research in Medicine \& Healthcare 2017; 1:138-146

doi:10.4081/qrmh.2017.7116 not very fit, or...I mean, the first thing you think of is that it's the illness coming back, isn't it?

Most people who have experienced cancer know that it is not a temporary disease. It can mark one's life also after therapy in the form of a great variety of physical, mental and societal difficulties. Bodily sensations may endure and influence the everyday activities of someone who has had cancer. They can suffer from cognitive limitations, sleep problems, fatigue, pain and physical limitations, which cannot easily be categorized as new symptoms, late effects or discomfort connected to other illnesses. The phase after cancer treatment is often marked by worries about indeterminate bodily sensations, which might be symptoms of possible relapse. ${ }^{1}$

Our experience of bodily sensations cannot be merely explained physiologically, but should also be examined as culturally embedded, and mediated by social practices and symbolic systems of meaning. ${ }^{2}$ Anthropologists have developed analytical approaches to elaborate the cultural and social meanings of sensations. Those mentioned below are just a selection of those who deal with the subject. For example, Hinton, Howes and Kirmayer ${ }^{3,4}$ show how interpreters of sensations refer to specific sensation schemas (which vary from society to society), to ideas evoked by a sensation, mental imagery or/and memories, so to emotion and cognition based circumstances, when interpreting a sensation at a given moment.

Howes ${ }^{5}$ explores the relationship between sensory experience and cultural expression. He criticizes the exclusion of sensuality from intellectual inquiry and reclaims sensation as a fundamental domain of social theory. Geurts ${ }^{6}$ shows how the five-sense model (taste, sight, touch, smell, hearing) is not generally applicable in all 
cultural contexts but rather how it is socially produced. $\mathrm{Hay}^{7}$ develops a sense-to-symptom model, where she draws on fieldwork from Lombok, Indonesia. She states that $[p]$ erceptional and interpretive decisions regarding what sensations need to be attended to as potential symptoms may be the result of personal awareness of cultural ideas about vulnerability, sensation duration, and interference with activities. ${ }^{7}$ Hay argues that research has not explored enough how people come to recognize a sensation as a symptom, and thereby become patients in the health care system. Since then, further research has been done to understand social processes of how bodily sensations are turned into symptoms, which has resulted in a better understanding of illness. ${ }^{8-10}$ Hay's perspective has been used to understand how U.S. veterans came to conceptualize their post-trauma suffering as post-traumatic stress disorder, ${ }^{11}$ or in analyses of pre-cancer processes. ${ }^{12,13}$ Brandner et al. ${ }^{14}$ used Hay's analytical suggestions to understand the social contexts of ovarian cancer patients' pre-diagnostic illness experiences and healthcare seeking. These authors show how the interpretation of bodily sensations as symptoms related to a possible cancer diagnosis is embedded within a social and cultural context. There is, however, a lack of research on how people who live in the aftermath of cancer treatment turn bodily sensations into symptoms. Analysis of how cultural and social norms shape the experience and understanding of bodily sensations during a phase after cancer treatment are scarce. ${ }^{15,16}$ Andersen, et al. 2010)

In Norway, between one-third and one-half of the population will be diagnosed with cancer at some point. Onefifth eventually die from it. ${ }^{17}$ Cancer survival rates are increasing in most cancer diagnoses in Norway and other European countries. ${ }^{18}$ This means that the number of people who live in the aftermath of cancer treatment is increasing, and many live with uncertainty and continue to worry about possible relapse. ${ }^{19,20}$ Many find that they are seen by others as cured, instead of being identified as people who are gradually transitioning from treatment to survivorship. ${ }^{21}$ This unclear status makes them face other challenges than those of acute cancer patients or other illness groups, particularly in terms of processes of bodily sensations turning into possible symptoms of the cancer coming back.

The aim of this paper is to explore the sense-to-symptom processes among people who have undergone cancer treatment and are back to most aspects of their everyday life, residing in a rural, coastal village with fewer than 3000 inhabitants in Finnmark, the northernmost county of Norway (undisclosed due to anonymity). The analytic focus is on experiences with the primary health care system and on shared values in the village. We assess Cameron Hay's (2008) definitions of sensation and symptom as the most applicable ones for this article:

A sensation is embodied; it is felt experience. By contrast, a symptom is a constructed and socially informed cognitive interpretation that indexes but is not itself an embodied sensation. ${ }^{7}$

Our argument is therefore inspired by Hay's (2008) work on understanding the social and cultural processes involved in how sensations become symptoms.

\section{Materials and Methods}

This analysis builds on the overall project SenCancer - Sensing illness in everyday life: Care-seeking and perception of symptoms among cancer survivors, at the University of Troms $\varnothing$, Norway. To be able to explore former cancer patients' sense-to-symptom processes, a qualitative research design was chosen, and the first author conducted one-year anthropological fieldwork in the North Norwegian village. The village faces the open Barents Sea to the north, and in the other directions partly hilly surroundings. Winters are dark, very windy (often $10-20 \mathrm{~m} / \mathrm{s}$ or more) and snowy. The short summers are foggy and life in the village is partly regulated by the extreme differences between summer and winter.

Most people in the village work in the service industry, the secondary sector of the economy, or the local health and care services. Even though the fishing industry has diminished over the years, it is still considered the main industry in the village. ${ }^{22}$ The village has a primary and secondary school to 10 th grade.

Due to the isolated geographic location and the twohour flight to the nearest hospital with an oncology department, people who live with cancer face challenges. Flights are often delayed or cancelled, which makes access to specialized health care unstable.

The first author was part of the everyday life and relationships in the village for almost one year. Four men and six women who lived in the aftermath of cancer illness and treatment were the core participants in the study. The local general practitioner and the cancer nurse recruited five participants, by asking a few of their patients or former patients, if they would like to meet the first author and take part in the study. The first author recruited three participants through acquaintances, and two through an advertisement in the local newspaper. Those who agreed to take part, were asked to sign an information letter and a written consent.

The participants' bodily experience of cancer started either with a surprising diagnosis, or days, weeks or months of uncertainty about something unusual in their physiology. During fieldwork, they were all in processes of resuming most aspects of everyday life, while still experiencing insecurity and worries about possible relapse. Nine had completed conventional cancer treatment. One participant still had cancer, which was kept at bay by three different radiotherapies at different points in time. The timespan since treatment among the nine who had completed varied between three months and 10 years at study start. The participants had different types of cancer, were 
between 41 and 82 years of age and had different career backgrounds. They had varying experiences related to the diagnosis and treatment, ranging from an uncomplicated operation four years ago to the experience of relapse and living with late effects of treatments. Four participants were back to work, one had to reduce her workhours after treatment and five were retired (Table 1).

The fieldwork involved biographical interviews and monthly semi-structured interviews conducted with the participants. ${ }^{23}$ The biographical interviews focused on participants' illness stories and took place early in the fieldwork. These formed a basis for the monthly semistructured interviews. The monthly interviews included questions about well-being, perceptions of bodily changes, bodily sensations, and symptoms. Participants were also asked about who was involved in their decisions about seeking care, their encounters with the health system, their reasons for choosing a particular care service and how they evaluated the health care services. Combining these methodologies allowed us to gain access to the participants' lived experience of bodily sensations and emotions in the phase after cancer treatment.

In February 2014, three days before the end of polar night, the first author started fieldwork in the village. She had already made a few advance contacts with staff of the health care centre in December 2013, so that some people expected her visit. Everyone knew everyone and her transition from being new in the village to meeting many acquaintances while walking along the street went fast. While going for walks in the village, joining friends, meeting regularly at a local café, chatting with people, singing in the local choir, knitting in the knitting club, and playing in the orchestra, she met both the participants and other inhabitants in many settings both regularly and by chance.

Inhabitants expressed mixed feelings to the fieldworker about the lack of anonymity in the village. Sometimes they experienced the close-knit society as comforting since it allowed people to care for each other, but sometimes it could be a strain that everyone is always updated about one's life.

As an example of an everyday social exchange, consider a daily 11 am coffee at the only local café in the village. The first author would sometimes join the participant Ole, when he met with other male pensioners for this morning ritual. If any of the regulars in the group did not show up, questions would be raised about their absence, as part of exchange of news and opinions on a broad range of topics, including cancer and health, death and illness among the villagers. More personal sharing of one's own illness or worries was, however, not really part of the coffee talk.

The analysis of participants' responses was guided by questions like: How does this lack of anonymity, and the experience that people talk and everybody knows about one's health and illness, influence bodily sensations and the process from sense to symptom among people living in the aftermath of cancer treatment in the village? How do they communicate sensations which might be symptoms of the cancer coming back? What do they share with co-villagers? How do they turn bodily sensations into something that the general practitioner or specialist should look into?

\section{Ethical considerations}

We refer to the Committee on Publication Ethics International Standards for Authors ${ }^{24}$ and confirm that our manuscript meets the required publication ethics. Participants provided informed consent and had the option to withdraw from the project at any point. They were assured that any information they provided would be treated with confidentiality and de-identified. Thus, all participant names have been changed. The community where the study was conducted was small, and descriptions which would reveal the identity of the informants were left out.

This project addresses the sensual, emotional and relational aspects of the patients' illness experiences. This means that patients and their significant others were vul-

Table 1. Overview informants-status 2014.

\begin{tabular}{|c|c|c|c|c|c|}
\hline Name/sex & Age & Recruited through & Occupation & Diagnosis-year & Civil situation/housing situation/children \\
\hline $\mathrm{Jan} / \mathrm{male}$ & 62 & Local health centre & Retired & Lung-2011 & Couple/lives most of the year by himself/2 \\
\hline Siri/female & 42 & Local health centre & Works fulltime & Ovarian-2010 & Couple/lives together with partner/0 \\
\hline Kari/female & 50 & Local health centre & Works fulltime & Breast-2010 & Couple/lives together with youngest son/3 \\
\hline Ole/male & 77 & Local health centre & Retired & Prostate-2009 & Single/lives by himself/2 \\
\hline Synnøve/female & 57 & Local health centre & Works $50 \%$ part-time & Colon-2002 | Lymph-2003 & Couple/lives together with husband/2 \\
\hline Ines/female & 57 & Acquaintance & Works fulltime & Breast-2013 & Single/lives by herself/0 \\
\hline Bjørg/female & 41 & Local health centre & Works fulltime & Ovarian-2013 & Couple/lives together with children and partner/ 2 \\
\hline Terje/male & 82 & Local health centre & Retired & Colorectal -2014 & Single/lives by himself/1 \\
\hline Gro/female & 69 & Local newspaper & Retired & Ovarian-2011 & Single/lives by herself/0 \\
\hline Torleif/male & 64 & Local newspaper & Retired & (still not cured but kept at bay) & Couple/lives together with partner/2 \\
\hline
\end{tabular}


nerable both during fieldwork and by being included in the analysis. We believe special care and sensitivity was needed to protect and respect the patients' integrity throughout the study. The research group worked specifically on these issues during the study.

Before we started the project, it has been presented to the Regional Committees for medical and health research ethics (REK) and found not bound to be assessed as health scientific project. It has also been reported to the Norwegian Data Protection Authority.

\section{Manoeuvring of sense-to-symptom processes}

Contributions to the common good (not wanting to be a burden to the healthcare system or others)

Bjørg: Do you go to the doctor if you have a bit of a pain in your stomach for a couple of days? And then it goes away. And the same with ovarian cancer: it comes and goes [...]

I don't go to the doctor because I've just felt it for two days. Then it turns out, after all, that I should have gone several years ago when I felt those symptoms coming and going. So it's hard to work out when you should go to the doctor, especially for me working in health care, I don't want to look like a hypochondriac. After all, it's my colleagues I'm going to. So to go there and say, "Well, now it's been like this and like that" one month before my check-up down in Tromso - that's hard. So it's like I maybe should have gone, but I'll wait till I get to Tromsø because I don't want people to think I'm a hypochondriac.

In everyday talk, the term hypochondriac is used for persons who pretend to be sicker than they actually are. In societies in which the understanding of illness is partly guided by clinical concepts, such a person tends to be seen as a burden, since she or he is taking up the doctors' time wastefully. ${ }^{25}$ Bjørg's statement shows her attempt to avoid being seen as a hypochondriac. She feels responsible for understanding her body, recognizing the reason for bodily sensations that appear and making responsible health choices. Bjørg is concerned about finding the right moment when she actually needs help, as she does not want to make use of the health care system unnecessarily.

Based on fieldwork in a suburban middle-class neighbourhood in Denmark, Offersen et al. ${ }^{26}$ show how...a moral relation between the Danish welfare state and the middle-class population is embodied in a responsibility for individual health. They show how participants attempt...to seek healthcare properly, i.e. by not burdening the system with trivial matters and at the same by reacting timely on symptoms and risks as a responsible person and good citizen. In the Norwegian periphery, social difference is structured differently, ${ }^{27}$ than that described by Offersen et al. ${ }^{26}$ and social difference is not the focus of our study. However, the participants in the village express similar concerns about being irresponsible or exaggerat- ing their symptoms and health, and they try to avoid being a burden to others and the health care system.

Being concerned about being a burden can be connected to not being able to live up to what is generally morally accepted in the village. People value co-villagers who care for the common good, participate in voluntary work, care for others, and have a positive attitude. Being anxious, concerned or hypochondriac can be experienced as negations of these values and the participants tried to avoid being associated with those attributes. The values can be exemplified in the appreciation of participation in the many dugnads in the village; these are voluntary and collectively performed activities for the good of voluntary organizations or the village as a whole. The regular participation in the cleaning up of the rubbish on the coast line is considered as one of those important dugnad activities. Dugnad has developed from the need to work together in groups to survive in traditional farming and fishing communities. Nowadays people do not depend on dugnad to survive in the Northern Norwegian coastal villages. The modern dugnad blooms especially in rural Norway, and is for instance arranged when buildings need to be repaired Nobody is obliged to organize or participate in a dugnad, but there is an implicit norm to get involved in it. ${ }^{28,29}$ People who for some reason do not participate risk being seen as non-contributors to the common good. ${ }^{30}$ Further, people who have a positive attitude, do not complain and do not give in to hardships are valued. One should not be on sick leave without good reason, and people find it demanding to be asked about work and sick leave by co-villagers such a topic is to be avoided if possible. ${ }^{22}$

For many of the participants, the possible symptoms of the cancer coming back could mean a setback practically and morally in terms of being unable to work, or having to reduce one's work and contribute less to other areas of life, like family and voluntary obligations. Having to see a specialist, which involves both a plane journey and taking time off work, is experienced as a standard procedure but also complicated.

\section{Positive attitude - how participants feel seen by others}

Synnøve: When you get one of those depressions, well, it's not a depression...I'm not that kind of negative person. I have a positive outlook.

Synnøve, had cancer twice and experienced phases in life in which she thought she might die soon. She was still concerned about relapse and explained how walking on one particular path in the natural surroundings close to the village became one way for her to deal with emotional or psychological difficulties, not only related to cancer but also non-cancer related situations. Although she struggled with those psychologically difficult periods, it was important for her not to be associated with depression. Synnøve associates having a depression with having a negative attitude. She is sporty, slim and suntanned, partly resulting 
from all her outdoor activities. During the interviews she would enthusiastically tell about trips with her husband, how she taught herself to ski while being pulled by her sons' dogs and how she and her husband tried to be outdoors as much as possible, especially when they were staying in their cabin, mostly at weekends. Synnøve enjoyed being seen as tough and active.

People in the village referred to Synnøve as a positive person, who managed to survive cancer, even though she was weak from treatment and was wheelchair-bound for some weeks. Not letting yourself get depressed and rather focusing on and talking about the positive things in life is appreciated by people, and the participants found it difficult to admit that they were not feeling well, either mentally or physically, or that they were worried.

Torstein: People won't ask how you are, because then they might get a whole dissertation about how you're getting on. People can't cope with that. They're maybe not interested in lots of details. People want to hear: "I'm fine".

Even though Torstein criticized people's attitude of not being able to handle bad news, he also seemed to adjust to it. He avoided appearing ill in front of others and having to burden people with his worries: I don't want to burden anyone with my complaints [...] and I don't want my grandchildren to think: "Poor sick old Grandad".

In line with Torstein comments about being a burden, Bjørg imagined how people might think she was mentally unstable, if she misinterpreted bodily sensations as symptoms of relapse:

Bjørg: What I'm really afraid of is appearing to be mentally unstable...You want to show people around you that... as long as you're off the sick list and all that, society or people around you kind of demand that you don 't... There mustn't be any more talk about it, you've got better and so on. [...] You ought to be happy, and such negative things shouldn't be mentioned. That's what society expects of you. When you're off the sick list, then you're well.

Later in the same interview, she explained that she often tried to avoid sharing newly appeared, indeterminate sensations with others. She would rather try to find information in books and on the Internet, for instance.

Participants experienced this phase of uncertainty, recovery and possible illness within a context in which it was not easy to talk about new alarming bodily sensations. Foss ${ }^{30}$ discusses the term a stå han av, which she translates as stand up in the storm (and has meanings like we'll manage, we'll get through or we'll survive), based on her ethnography in a small coastal community of Northern Norway. The term was used in different contexts to illustrate the northern Norwegians' strength of charac- ter, and it describes people who do not give up, even when they experience overwhelming hardships. It is an old expression from earlier times of poverty and extreme weather, and is today a symbol of identifying with Northern Norway and its culture, which is associated with people's strength, resilience and strong social cohesion, qualities which people are proud of. ${ }^{30}$

In this section we showed how a culture of trying not to be focused on difficult things in life and one's own worries and negative thoughts was part of the participants going through a phase of uncertainty and increased alertness regarding their body and possible processes of bodily sensations turning into symptoms. Not wanting to exaggerate, wanting to be seen as a contributor and the value of a positive attitude all played a significant part in how sensations were assessed by the participants. They tried to avoid involving others in their first experience of indeterminate bodily sensations, as it might be connected to being negative and hypochondriac. They felt uncomfortable when misinterpreting indeterminate sensations and had inner dialogues about other people's possible reactions. The participants played down uncertainty and negative feelings and tried to manage to assess the sensations by themselves.

\section{Clinical logics and the lack of GPs in rural primary health care}

In this section, we illustrate how high turnover in local primary health care in the village is relevant to the participants' sense-to-symptom processes connected to cancer. Primary care is the participants' key point of contact for referral to treatment and check-ups by specialists, and the implementation of clinical logics within health care institutions in general.

Torstein, reveals how he had lived with non-Hodgkin's lymphoma since 2003 , which had so far been controlled with three different radiotherapies, in a conversation with the first author. He explains how, during a recent consultation with a temporary GP, he had to introduce himself from scratch, and state why he came to see him, even though he had met him for the first time a few weeks before. He found the GP to be overwhelmed by his sole responsibility for the village, which meant he would continually meet new patients, while at the same knowing that he would leave the village again in a few weeks, and thus would not engage with patients in the same way as a permanent GP would do.

Torstein: [...] He was badly prepared. Because I noticed a patient before me who went out. And then I was called in straight after that. I don't think he read my record. Well, I took things the way they were. I told him why I'd come [...].

M: Mhh.

Torstein: It was...

M: Oh I see, he wasn't sure why you'd come that day? 
Torstein: Yes. He asked "So what's the matter with you then?" [...] But I explained it to him bit by bit... and then he understood.

M: I see. I didn't know... Will he stay here long or what?

Torstein: No...I don't know if he's employed here, or...I didn't ask that but he speaks Swedish. He kind of had Norwegian with a Swedish accent. [...] But it's really strange about these doctors. They're hired by one of those firms, that hires them out.

M: Mhh.

Torstein: So you have to take what you get. It's a problem in all rural areas to get hold of doctors. Doctors want to be in big hospitals, they want to be teams and maybe not have the responsibility of "I'm here all by myself".

M: $M h h$.

Torstein: So...no, we have to live with it. Those GPs or primary doctors, as I call them. So if you have a problem then you should be quite focused on moving up in the system. Don't let some doctor decide on the outcome if you have a symptom that's quite obvious. If you have something that's quite diffuse, backache for example or...that it's hard to define, well then it's...Then maybe it can stay with the GP for a bit, because he doesn't know how to send you on. I mean, to give you priority in the system.

M: So you mean you have to sort of...keep at it... Torstein: Yes!

Torstein's experience is that his bodily sensations ought to be specific enough to be presented in a consultation. Previous research shows how the presentation of indeterminate sensations can lead to not being referred to see a specialist, and hence in diagnosis delay ${ }^{33}$ Andersen and Vedsted ${ }^{34}$ show how a culture of inappropriateness of presenting diffuse and indeterminate bodily sensations or worries during a consultation means that patients have to wait until the sensations become more clinically relevant. Torstein's reflections show how the temporary position of the local GP and his unfamiliarity with the patients intensifies the patients' needs to be focused and clear in their communication of possible symptoms when seeing him.

While the first author was staying in the remote village, the local council employed a general practitioner, who had already lived there for a couple of months and communicated his plans to stay for some length of time. Some conversations with residents, study participants and a nurse from the local health centre revealed that this was an exception. The local health centre was marked by high turnover. In the five years from 2008 to 2012, 16 GPs and four physiotherapists had started to work in the village and left again, interspersed with periods with no such services. ${ }^{22}$ Patients found that they had to start consultations from scratch, and to repeat information about themselves over and over again. ${ }^{22}$ People in the village would try to take this situation in good humour, and often said: Well, we wouldn't call it fastlege. They hint at the ironic meaning of the word fastlege, which is the Norwegian term for GP or one's regular doctor, but could also mean permanent doctor.

Working in primary health care in a rural area is the least popular choice among health personnel, partly because GPs often have the sole expertise and clinical responsibility for an entire local authority area. ${ }^{31}$ These are some of several factors why GP contracts are more than three times as long as in local authorities with over 50,000 inhabitants than in those with fewer than $2000 .{ }^{31}$ Understandably, small communities are more vulnerable to the lack of a GP than larger ones. ${ }^{32}$

In addition to the challenge of short employment periods of the local GPs, the local health centre is embedded in a health care system based on clinical logics, with requirements of effectiveness and a biomedical understanding of the human body, which also affects participants' sense-to-symptom processes. Participants have certain understandings of what could be presented in a consultation and what is appropriate to ask for from previous experiences with the health care system. Conversations with participants like Laila show how this affected her experience and handling of bodily sensations. She was in her 50s and was diagnosed with breast cancer four years ago. During the fieldwork period, she felt generally well, but was noticing high blood pressure from time to time. Whenever she perceived this or did not feel well, she immediately thought cancer might be on its way back. In the following interview section, she expressed a wish to get a sort of comprehensive overall medical examination to be able to understand why particular sensations appear. But she explained how such an examination is usually not part of her routine checks, and she made use of a kind of rational reasoning to justify in the interview that her wish was out of the ordinary.

Laila: Is there any metastasis? Have I got cancer anywhere else? [...] You just have to... you've got to believe you're ok. As long as nothing else has been found. So well, but what I'd really like, I'd like it if you had a, like, a proper examination of not just the breasts but the rest of the body too, in terms of cancer. [...] Afterwards. And going round wondering and thinking about it: "Could it be something?" [...] Because it's obvious, when you have breast cancer, it's only your breasts they examine, nothing else.

It would have reassured Laila if she could have had a full body examination, hence she was dissatisfied with the GPs' usual choice of examining only her breasts. She pointed out the possible consequences of this decision, for instance that a relapse might remain undetected. The participants experienced concerns or indeterminate sensations, such as worrying when feeling in bad shape, but 
found it difficult to present this to the GP. Laila related to the physician's possible assessment when experiencing bodily sensations, and the GP's imagined reaction was part of her evaluation of whether a sensation might be a symptom or not. This shows how clinical logics in the health care system play a part in how participants understand illness, their physical body and cancer, and how they experience cognitive limitations, sleep problems, fatigue, pain, physical limitations or a general sense of feeling unwell, signs which could be understood as concrete symptoms of relapse.

The participants in this study would often use clinical terms in their everyday language, such as relapse, diagnosis or metastasis, which symbolizes how illness and body were experienced in terms of a biomedical understanding. Previous research points out how patients reconfigure their concerns to fit the local clinical setting, ${ }^{34}$ and it is therefore not surprising that Laila tried to balance her worries connected to indeterminate bodily sensations against the possibility of the GP seeing her as hysterical.

Laila: So if I've got high blood pressure or my foot hurts, I think of cancer. So I thought, well ok, if he [the $G P]$ is willing to send me for an X-ray, well, then I'd like that. Yes. So he should do that. I said he could write in the referral letter that it was a case of a hysterical old woman.

Laila was in an ambivalent situation. She was afraid of not being referred to a specialist by her GP for an Xray, but was also concerned about assessing her sensations wrongly and making unnecessary choices involving the use of her GP's resources. She felt that her partly indeterminate sensations hardly fitted in to the clinical framework of the meeting with her doctor. In this situation, her worries became too uncomforting, which eventually made her see the GP, but triggered a feeling of exaggerating too much.

Bodily sensations are not always clear or connectable to a specific cause, but often rather diffuse and do not represent a clear sign of a particular diagnosis. ${ }^{34}$ Moreover, sensations are individual and therefore the experience of discomfort or pain can mean different things to different individuals. Synnøve, for example, had had two different types of cancer (colorectal and Hodgkin's lymphoma) at different points in her life and was now living with chronic, daily pain in her joints, especially her feet, which she usually assessed as late effects of chemotherapy. Sometimes, however, she experienced moments of doubt. When Synnøve tried to understand her pain, she was not always sure whether it might be a symptom of a new diagnosis, the result of an exhausting day at work or influenza coming on. She found this confusing, especially because medical specialists had previously explained to her that she had a high threshold of pain, which was one reason for being diagnosed with cancer when it had al- ready reached an advanced stage. Clinical practice and its foundation, a medically conventional approach to the body and illness, suggest patterns of how certain illnesses are experienced, what kind of sensations and pain are connected to them, how strong they usually are and where they are located. ${ }^{35,36}$ The health care personnel signalled to Synnøve that she had sensed alarming symptoms as not strong and early enough, and that other patients would have come earlier with a suspicion of cancer. Hence, she became conscious about her own sensibility to bodily changes and anxious as to whether she might overlook something. ${ }^{34}$

Both Laila and Synnøve embody and include clinical routines in their perception and assessment of bodily sensations, and in questions like: What shall I do about them? Embodying those routines is part of their experience of their body and worries as something atypical and it both questions and informs the justification of their senses. In this way, they will either backpedal from judging a sensation as a symptom and consulting the doctor, or experience it as an encouragement or confirmation to actually contact the doctor.

In this section, we showed how participants assessed indeterminate bodily sensations in relation to previous experiences in consultations and clinical practice in health care settings. Sensations should preferably be specific enough to be presented in a consultation and thus clinically relevant. The often temporary stay of the local GP and his or her unfamiliarity with the patients can intensify the requirement to patients to be focused and clear in their communication of possible symptoms during consultation. The consequences for participants' sense-to-symptom processes were that they tended to wait until they consulted the doctor or tried to make sensations fit into the clinical setting and connect them to a definite sign of a specific diagnosis, which had the potential to result in a delay in diagnosis and treatment. While the participants referred to how they sometimes experienced their bodily sensations and worries as indeterminate, they conducted inner dialogues, not only as presented in the previous section with other villagers, friends and family, but also with health care personnel, including assumptions about how these might react to the presentation of the indeterminate sensations and how consultations might turn out.

\section{Discussion}

\section{The significance of social legitimation for symptoms}

We have shown how aspects of the challenging local health care situation, embedded in an institutionalized clinical system, together with the local shared values, were embodied by the participants, and played a role in their sense-to-symptom processes. They led to inner dialogues with potential others, concerns about overreacting to sensations, being a burden to others and being seen as 
hysterical by co-villagers and the GP. These are all normsetting factors suggesting certain frames of normality, in terms of how the participants are supposed to react to certain sensations and how to act in their roles as former patients, officially tumour-free and recovered from cancer.

In her article, $\mathrm{Hay}^{7}$ suggests a model illustrating how social and cultural processes are involved in how sensations become what are medically known as symptoms. Even though Hay bases her analysis and the model on specific empirical data from her fieldwork in Lombok, Indonesia, she suggests its application also in other groups under study, in order to explore sense-to-symptom processes from an anthropological perspective.

In this concluding discussion, we consider it fruitful to compare it with Hay's work, since this provided inspiration for the analysis process of this paper. In line with our results, we conclude by contributing additional analytical aspects to her suggestions for the exploration of sense-to-symptom processes.

Her data suggest ...that people seek care based on their judgments that a sensation exceeds acceptable temporal spans or disabilities, or that it fits within their expectations based on experiences of vulnerability (Hay, 2008). She describes how individuals in her studied group of Sasaks ...would verbally mark their experience of vulnerability with the phrase "I am not brave enough" and how they read and reread sensations, interpreting them as symptoms when there is an emotional-cognitive awareness of vulnerability. She shows how the perception of time is a decisive frame for judging the significance of a sensation and that [i]f sensations are seriously disruptive, they tend to be rapidly reinterpreted as symptoms worthy of outside attention. In other words, she argues that these three crucial aspects (personal awareness of cultural ideas about i) vulnerability; ii) sensation duration; iii) interference with activities) can be useful in understanding patient sensations as cultural and social phenomena as well as physiological ones. ${ }^{7}$

Hay's aspect of vulnerability is crucial in considering the sense-to-symptom processes of our participants, and is more significant, it seems, than it is for Hay's participants and analysis, since the very experience of a lifethreatening illness like cancer makes people very aware of suffering possible relapse. Our key participants were clearly vulnerable. However, in our analysis we were able to locate other aspects relevant to the sense-to-symptom processes of the participants of our study; these were aspects which Hay does not mention in her analytical considerations. While Hay points out the relevance of the above-mentioned aspects sensation duration and interference with activities, we see circumstances like the atmosphere in the village, with its specific moral values, and the nature of clinical routines, which are reinforced by the high turnover of GPs in the village, as much more decisive for how and if a sensation was turned into a symptom by participants.
Another aspect of Hay's considerations is that [t] hose sensations that are interpreted as worrisome are then presented to others, seeking social legitimation. People talk with others - neighbors, friends, acquaintances - about their sensations, describing and sensationalizing them, testing the boundaries of whether they could be symptoms. Hay sees the social interaction around the interpretation of the sensation as a symptom as a step that occurs after one has considered whether the specific sensation experience fits with vulnerabilities or exceeds the expected duration or tolerable disability. In our analysis, we are able to show how this is different for our participants: when they assessed the significance of a sensation, they were aware of the local healthcare situation and possible judgements by health care personnel. Moreover, their perception of sensations was also strongly influenced by their sense of not wanting to focus on negative things or to be hypochondriac or exaggerate excessively, and they therefore conducted inner dialogues concerning the possible judgements of other villagers. That is why we see the processes of social legitimation as already being a significant part of the assessment of bodily sensations. This is a major difference from Hay's analysis in which she states that [o]nce a threshold of one of these frameworks is crossed, a person recognizes that "something is wrong here." And at this point, it appears to be crucial that that subjective evaluation is legitimated in a social arena. Even though our participants wait until they actually discuss and verbalize sensations, worries and speculations with others, the imagined potential others, who might have strong opinions, are already part of perceiving a sensation and not only of legitimating a symptom. We suggest that the social and cultural processes influence the sense-symptom process earlier than Hay suggests in her analysis; social legitimation and acceptance are already part of the assessment of bodily sensations and of a process simultaneously informed by sociocultural and medical values.

We have illuminated an important discussion connected to the life phase after cancer treatment. This article can be seen as a contribution to the anthropological discussion on senses in general, but especially to a better understanding of how social norms and local health care conditions influence sense-to-symptom processes of former cancer patients in rural Northern Norway. Previous research has shown how primary health care is facing challenges in some rural areas of Norway, and this article shows how this has significant consequences for people living in the aftermath of cancer treatment. Medical examinations in primary health care are crucial for referral to a specialist, especially for patients with chronic diseases and those who have to be followed up. Our data shows how this situation is challenged and further steps must be taken to ensure continuity in primary health care in rural areas of Norway. We suggest that further research could clarify whether the population in such areas actually has to overcome a greater inhibition 
threshold before contacting their GP than people in larger, more anonymous places.

\section{References}

1. Harrington CB et al. It's not over when it's over: long-term symptoms in cancer survivors - a systematic review. Int J Psychiat Med 2010;40:163-81.

2. Classen C. Foundations for an anthropology of the senses. Int Soc Sci J 1997;49:401-12.

3. Hinton DE, Howes D, Kirmayer LJ. Toward a medical anthropology of sensations: definitions and research agenda. Transcult Psychiat 2008;45:142-62.

4. Nichter M. Coming to our senses: appreciating the sensorial in medical anthropology. Transcult Psychiat 2008;45:163-97.

5. Howes D. Sensual relations. Engaging the senses in culture and social theory. Ann Arbor: The University of Michigan Press; 2007.

6. Geurts KP. Culture and the senses: bodily ways of knowing in an african community. Berkeley: University of California Press; 2002.

7. Hay MC. Reading sensations: understanding the process of distinguishing 'fine' from 'sick'. Transcult Psychiat 2008;45:198-229.

8. García-Hernández KY et al. This plant treats that illness? The hot-cold system and therapeutic procedures mediate medicinal plant use in san miguel tulancingo, oaxaca, Mexico. J Ethnopharmacol 2015;163:12-30.

9. Rosendal M et al. Multiple perspectives on symptom interpretation in primary care research. BMC Fam Pract 2013;14.

10. Bagayogo IP, Interian A, Escobar JI. Transcultural aspects of somatic symptoms in the context of depressive disorders. Adv Psychosom Med 2013;33:64-74.

11. Spoont MR et al. From trauma to ptsd: beliefs about sensations, symptoms, and mental illness. Qual Health Res 2009;19:1456-65.

12. Andersen RS et al. Patient delay in cancer studies: a discussion of methods and measures. BMC Health Serv Res 2009;9.

13. Andersen RS et al. 'Containment' as an analytical framework for understanding patient delay: a qualitative study of cancer patients' symptom interpretation processes. Soc Sci Med 2010;71:378-85.

14. Brandner $\mathrm{S}$ et al. Symptomization and triggering processes: ovarian cancer patients' narratives on pre-diagnostic sensation experiences and the initiation of healthcare seeking. Soc Sci Med 2014;119:123-30.

15. Youll J, Meekosha H. Always look on the bright side of life: cancer and positive thinking. J Sociol 2013;49:22-40.

16. Brandes $\mathrm{K}$ et al. Unraveling the determinants of cancer patients intention to express concerns. J Health Commun 2016;21:327-36.

17. Larsen IK. Cancer in Norway 2014. Cancer incidence, mortality, survival and prevalence in Norway. Oslo: Kreftregisteret Norge; 2015.

18. Coleman MP et al. Cancer survival in Australia, Canada, Den- mark, Norway, Sweden, and the UK: an analysis of population-based cancer registry data. Lancet. 2011;377:127-38.

19. Olsen RE. Towards a sociology of cancer caregiving: time to feel. Surrey, England: Ashgate; 2015.

20. la Cour K, Johannessen H, Josephsson S. Activity and meaning making in the everyday lives of people with advanced cancer. Palliat Support Care 2009;7:469-79.

21. Miller LE. 'People don't understand that it is not easy being a cancer survivor': communicating and negotiating identity throughout cancer survivorship. South Commun J 2015;80.

22. Folkvord S, Foss N. Kombinering av konvensjonell og alternativ behandling ved lettere muskel- og skjelettlidelser 201317 August 2015. Available from: http://munin.uit.nobitstream/handle/10037/5788/article.pdf?sequence=1\&isAllowed $=\mathrm{y}$.

23. Flick U. Qualitative Sozialforschung. Eine Einfuehrung. Hamburg: Rowohlt Taschenbuch Verlag; 2012.

24. Wager EAK. Responsible research publication: international standards for authors. A position statement developed at the 2nd world conference on research integrity. In: N MTS, ed. Promoting research integrity in a global environment. Singapore: Imperial College Press/World Scientific Publishing; 2011. pp 309-316.

25. Damsgaard JB et al. Back pain: a feeling of being mistrusted and lack of recognition: a qualitative study. Int J Orthopaed Trauma Nursing 2016;21:11-20.

26. Offersen SMH, Vedsted P, Andersen RS. The good citizen: balancing moral possibilities in everyday life between sensation, symptom and healthcare seeking. Anthropol Action 2017;24:6-12.

27. Gullestad M. Det norske sett med nye øyene. Oslo: Universitetsforlaget; 2002.

28. Aarsæther N. Håkon lorentzen og line dugstad: den norske dugnaden. Historie, kultur og fellesskap. Sosiologisk tidsskrift. 2012;20:98-101.

29. Dahl KV. Fikk regning da hun ikke møtte på dugnad. 23 april. 2015. Available from: www.Byavisa.no.

30. Foss N. Nerves in northern norway: the communication of emotions, illness experiences, and health-seeking behaviors. Qual Health Res 2002;12:194-207.

31. Sollien K. Fastlegene flykter fra distriktene. 01 February 2016. Dagens Medisin.

32. Abelsen B, Gaski M, Brandstorp H. Fastlegeordningen i kommuner med under 20000 innbyggere. Tromsø: UIT Norges arktiske universitet NSDM; 2016.

33. Evans J, Ziebland S, McPherson A. Minimizing delays in ovarian cancer diagnosis: an expansion of andersen's model of 'total patient delay'. Fam Pract 2006;24:48-55.

34. Andersen RS, Vedsted P. Juggling efficiency. An ethnographic study exploring healthcare seeking practices and institutional logics in danish primary care settings. Soc Sci Med 2015;128:239-45.

35. Good BJ. Medicine, rationality, and experience: an anthropological perspective. Cambridge: Cambridge University Press; 1994.

36. Mol A. The body multiple: ontology in medical practice. United States of America: Duke University Press; 2002. 